\title{
Factors Affecting the Learning Process of Professionals in Architectural Design Firms
}

\author{
G.B. Ozturk-Barlak \& D. Arditi
}

Illinois Institute of Technology, Chicago, Illinois, USA

H.M. Gunaydin

Izmir Institute of Technology, Gulbahce, Urla, Izmir, Turkey

S. Kale

Balikesir University, Balikesir, Turkey

I.Yitmen

European University of Lefke, Lefke, TRNC

\begin{abstract}
Learning is considered to be a sophisticated process and a source of competitive advantage. Learning is essential in project-based environments. The one-of-a-kind structure of the operations of architectural design firms triggers special learning needs and requires a continuous learning activity. Learning is considered to improve an architectural design firm's efficiency by recognizing the role of individuals in enhancing the firm's objectives. However, theoretical research on individual professionals' learning process in the architectural design is rather uncommon. The process of individual learning is composed of (1) data acquisition (2) assessment of the acquired information and (3) implementation of the knowledge gained in a group setting. Ten factors were identified to assess the effectiveness of the learning processes of professionals. This study is the first study in the field of architecture that presents a conceptual model about the factors that affect the effectiveness of the learning process of professionals.
\end{abstract}

\section{INTRODUCTION}

Learning in a firm is composed of individual learning, group learning, and organizational learning. Individual learning has an important role in promoting group learning, which in turn enhances organizational learning. The learning process enhances success and competitive advantage for organizations. Group performance and organizational outcomes are enhanced a great deal by individual learning, because project groups and a firm's organization are composed of individuals. The linkage between individual learning and other levels of learning is of course important but will be treated in future research. The model presented in this paper is confined only to the individual learning process.

The concept of learning has been studied by many researchers (e.g. Shrivastava 1983, Levitt \& March 1988, Huber 1991, Miner \& Mezias 1996, EasterbySmith 1997, Tsang 1997, Sharma 2001). A firm's learning effectiveness lays in individuals' wisdom, which should be identified as a strategic asset and managed to contribute to the firm's performance and competitiveness. To develop added value to the firm, awareness and activation of individual learning is necessary. Individual learning encompasses the acquisition and creation of new knowledge, and depends on the role of people in the creation and utilization of knowledge. Individual learning in architecture depends on the psychological and physical condition of a professional operating in the work environment of an architectural design firm.

Learning is accepted as a source of competitive advantage, but the methods involved in achieving this advantage are not specified (Ghosal 1987, Edmonson \& Moingeon 1998). No research has so far been conducted to study how individual learning affects the competitiveness of architectural design firms. The study reported in this paper is the first study that has adopted the use of factors in the study of the effectiveness of the learning process of professionals in architectural design firms. The research seeks an understanding that outlines how learning processes happen in individual professionals employed by architectural design firms. It attempts to develop a model that describes and explains the critical factors that affect the effectiveness of the learning process of professionals in architectural design firms. This paper reports on the outcome of an extensive literature survey that identifies these factors. 
The learning process of an individual is composed of (1) data acquisition, (2) assessment of the acquired knowledge, and (3) implementation. After reviewing the learning phenomenon in Section 2, the paper briefly discusses learning in the context of architectural design firms, and presents the proposed assessment model.

\section{LEARNING}

The literature on learning has grown rapidly over the past few years. However, most contributions focus on the conceptual level and generally describe the impact of learning (Easterby-Smith \& Araujo 1999). Learning is identified as a strategic asset. It is an essential investment in individuals. It increases the level of an individual's capability to meet strategic goals and objectives. It is embedded in the management culture and in the organization's management support systems. Learning is a process that includes mechanisms that allow the development of knowledge, skills and behaviors.

\subsection{Learning process and levels}

The learning process starts with perception and ends with action. Perception is the experience that shapes intuition and adapts the new knowledge to respond to the external environment. Perceptive learning strategies are used to take the emotional barriers off the learning environment. The aim is to pay attention to keeping continuous focus, coming over the fear of action, and maintaining and sustaining motivation. The negative effects include attention dispersal and distrust. In contrast to perception, cognition encompasses memory, emotions, habits, reasoning, imagination, and planning. Cognition deals with attention, the ability to concentrate while restricting irrelevant distractions, and negative emotions such as fear and stress. The cognitive process includes habitual behaviors. Actions represent the final output of the brain and the means by which one exerts one's influence on the world. Learners must be physically and intellectually capable of producing the action.

Learning allows an individual to be ready to react in a changing environment and at least to keep the standards. Learning is a process that consists of several stages where the data collected by individuals are transformed into knowledge that is eventually used in projects. According to scholars, these stages have a cyclical nature (Kolb 1976, Kofman 1992, Schein 1993, Nonaka \& Takeuchi 1995, Buckler 1996, Crossan et al. 1999). The first stage of the learning process involves data acquisition. Data acquired by individuals are represented by individuals in a useful form for the related project requirements. Data are converted into information in the second stage of the learning process. It is in the third stage that information is converted into knowledge.

The learning process was studied by many scholars. For example, Kolb (1976) defined for the very first time a learning cycle that involves (1) observation, (2) formation of concepts based on gathered data, (3) test of concepts in different conditions, and (4) concrete experience. Similarly, according to Kofman (1992), individuals first observe and assess, then design the action to be taken, and finally implement the designed concept. Similar to Kofman's (1992) and Kolb’s (1976), in Schein's (1993) model, learning starts with observation, is followed by emotional reaction dependent on past experiences, and an intervention. According to Buckler (1996), the learning process is a little more involved than the previously cited models and encompasses psychological actions individuals take while learning, including reflection, enactment, commitment, understanding, awareness, and ignorance. Along the same lines as Buckler (1996), Nonaka \& Takeuchi (1995) assume that knowledge is socialized, combined, externalized, and internalized by an individual. On the other hand, the four levels of learning proposed by Crossan et al. (1999) simply refer to intuiting, interpreting, integrating, and institutionalizing. Throughout the feed-forward and feedback processes in this model, the interactive relationship between cognition and action is critical; one cannot be divorced from the other (Neisser 1976). One way or the other, these researchers are all shaping approximately the same understanding of learning. The overall consensus in the literature appears to indicate that the learning process is composed of data acquisition, assessment, and action.

\subsection{Drivers and barriers of individual learning}

Cognitive learning theories deal with the necessity of increasing learning responsibility and effective participation in the learning activity. Learning strategies are the processes that are used by individuals to learn by themselves. The individuals who can learn themselves are called 'strategic learners', 'independent learners', or 'self-regulated learners' (Ertmer \& Newby 1996). The strategies that are used by strategic learners include attention, repetition, and interpretation. Attention is the most important part of data acquisition from the environment and storage to the short-term memory. Repetition does away with the limitations of the short-term memory. Learners must not only recognize the observed behavior but also remember it at the right time and in the right environment. Interpretation involves knowledge transfer and storage into the longterm memory. The individual must have initial knowledge to interpret the new knowledge and must relate the new knowledge with the existing one. 
Because it is a dynamic process, learning should be continuously motivated. Motivational theories such as management by threat, Maslow's hierarchy of needs (Maslow 1954), McGregor's theory X theory (McGregor 1960), and Herzberg's enrichment and hygiene factors (Herzberg et al. 1959) were reviewed by Halepota (2005) in the context of the construction industry. In addition to the factors considered by the researchers, there are unconscious motives and innate drivers of individual learning. These drivers are different from one individual to another. One of the drivers of learning is learned habits. They are concrete experiences of prior learning activities. Learning can also be driven by reinforcers, i.e. "consequences" that strengthen behavior. For example, rewarding an individual may trigger one to accomplish the given task. Herein, the reward is called a positive reinforcer. Punishing one for not accomplishing the given task within requirements is called a negative reinforcer. In each case, one tries to finish the given task within requirements for reward or not to be punished. Reinforcers form an image of consequent processes in people's minds. Workers start to expect a reward for doing their job or start to work not to be punished. Scholars are not in agreement about whether rewards or punishment have a positive relationship with learning efficiency, because sometimes one may end up with a mistrustful working environment that may damage working conditions. It is important to know that a reinforcer may motivate an individual to learn, whereas the same reinforcer may act as a barrier for another individual. If one wants to maximize learning efectiveness, reinforcers or punishers must be contingent, immediate, of the right magnitude, and continuous.

Another driver of learning includes enjoyment of the work and of the work environment. If an individual is satisfied with the work environment and working conditions, then this individual can be productive and efficient in learning. Standardization in procedures eases the learning process. Discrimination of valuable efforts motivates people to learn. Clearly set statements in a firm's goals and vision enable people to know their target. This allows individuals to focus on their professional areas and lets them to learn in depth.

Architectural professionals also face several barriers to learning that stem from the project-based environment of architectural design firms, the immediate work environment, and each individual professional's background and attitude.

Every construction project is unique. Not only do architectural design firms have to deal with the general goals of the project, but they also need to satisfy the requirements imposed by site conditions and by the owner along the project execution period. Issues related to the work environment include but are not limited to transportation to project site, safety regu- lations, salaries and wages, time constraints, physical working conditions, shifts in work places, and overtime work. An unfavorable work environment may negatively affect the effectiveness of the learning process. In addition to project conditions and the work environment, a professional's learning process is also affected by individual perceptions, backgrounds and attitude. For example, a firm's identity may cause professionals to have a sense of security, but also sometimes a sense of fear of not being able to deal with the required task or not being knowledgeable enough for the job. Individuals are also affected by barriers related to management strategy and leadership such as lack of clarity of mission and vision, weak feeling of empowerment, and resistance to change.

\section{INDIVIDUAL LEARNING IN ARCHITECTURAL DESIGN FIRMS}

The research focuses on the learning process relative architectural professionals. As seen in Figure 1, it involves the acquisition of architectural data, and the assessment of architectural knowledge. Individual learning is often assumed to be a conscious and analytical process by scholars (e.g. Shanks \& St. John 2005, Sarasvathy \& Menon 2004, Stewart 2001; Weick et al. 1999, March 1994, Schollhammer 1991). Freud also believed that everything that a human being becomes aware of is stored in that individual's consciousness. As seen in Figure 1, data acquisition involves gathering architectural information through intelligence, experience, observation, creative skills, and intuition. While intelligence, experience, and observation are cognitive processes, creativity and intuition focus on the subconscious process of developing insights. Assessment of architectural knowledge consists of the interpretation of the acquired information through reflection in order to generalize it and make it ready to form concepts. Through the assessment process, individuals develop ideas about various domains such as architectural details, materials to be used, management of the design process relative to industry standards or benchmarks observed in other firms. Reviews are then conducted, the results are interpreted, and judgment is posted. This process involves conceptualization of the knowledge by interpreting past and new knowledge. Finally, the individual has to take action. An individual's action can have immediate impact or can be of value in generating group interaction. This research encompasses the data acquisition and assessment phases which are directly related to the individual professional and which result in action. Group interaction is related to a set of individuals and leads to organizational learning. Learning at the group and at the firm level will be treated in future research. 
Research efforts recognize the importance of learning in architectural design firms. The architectural design process has been described as a multiparticipatory distributed design environment (Huang 1999). Architectural design professionals' experience and knowledge have important value if reused in successive projects. Because of the project-based nature of the industry, professionals in architectural design firms are faced by significant challenges. The one-of-a-kind characteristic of construction projects forces design professionals to continuously learn. fessionals. Individual skills, intuitive abilities, integration capabilities are important to achieve success in learning. The capability of an individual directly affects the learning process, and the outcome of learning.

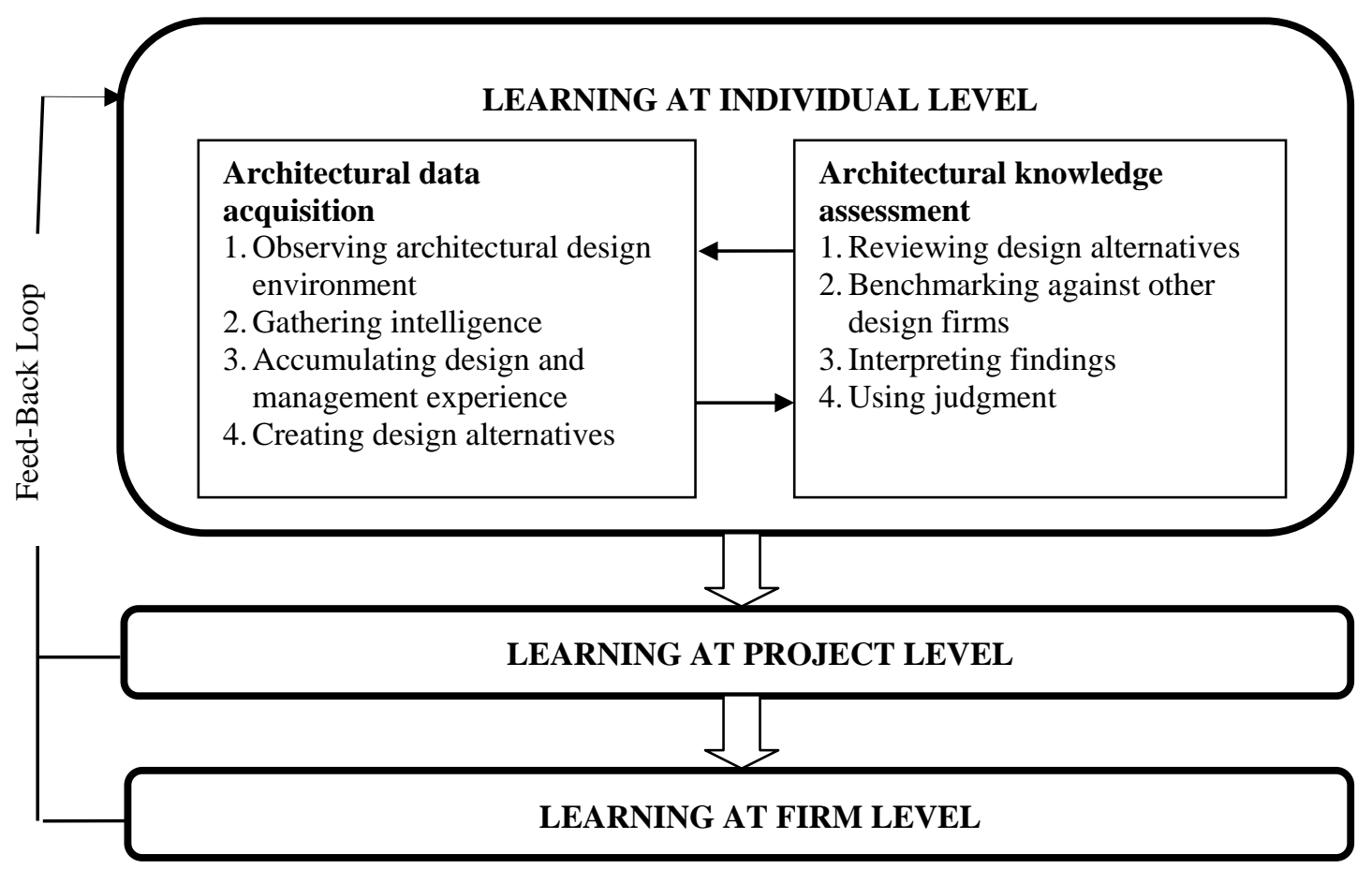

Figure.1 Learning Process in Architectural Design Firms

In the field of architectural design, the professionals' knowledge is tacit. It is difficult to capture, store and reuse. Kikoski (2004) and Bosch (2004) point out that tacit knowledge in architectural design firms includes design decisions, the design requirements, needs, constraints, natural talent, formal education, experience, taste, preferences, judgment, and skills. Knowledge totally belongs to individuals. The knowledge of the professionals in architectural design firms includes design capability, expertise, intuition, and design experience. It is used in reviewing projects, evaluating the impact of changes in assumptions and design decisions, forming a timeline of the design process, and classifying the stakeholders by their importance relative to the decision-making process (Kikoski 2004). Throughout the life cycle of a design project, architects rely heavily on their tacit design knowledge to support design decisions (Schon 1983). Because of this reason, architectural design firms attach great importance to design knowledge and expertise in their hiring and firing practices. Architectural design firms' tacit environment makes learning difficult for pro-

\subsection{Proposed individual learning model for architectural design firms}

Professionals with learning opportunity are developing skills to accumulate wealth for their firm. Based on the drivers and the barriers of the learning process described in Section 2, the factors presented in Figure 2 can be used in assessing the effectiveness of the learning process of professionals working in architectural design firms. The learning "wheel” can turn only if all the spokes are strong.

I.Pride in work and in firm: If professionals have a work place that they can be proud of, they will repay with hard work and loyalty (Alavi 2004, White 2009). Professionals' feeling of belonging and dedication to their firm is related to the conditions of the work environment. The level of pride is determined by the firm's reputation relative to the number and visibility of the projects designed for domestic and international markets. Pride exists in terms of inner self-satisfaction of accomplishment and the 
outer prestige. Pride is a potential motivator and a powerful force for cultivating learning. The consistent demonstration of the contribution of a professional to the well-being of the firm is a big part of generating pride in the work place (Crossan et al. 1999, Lehesvirta 2004, Prieto 2005, Chonkoa et al. 2003, Martin et al. 2006, Bontis et al. 2002). To build pride, four essential ingredients are needed, namely an inspiring corporate mission statement, a clean and attractive work environment, up-to-date and user-friendly technology, and learning opportunities. Learning new skills is a result of a firm creating opportunity. The more professionals learn and the more they get involved, the greater their pride in environment characterized by several competing interests, and needs to take steps to absorb new knowledge, or reintegrate and utilize its already existing knowledge, the firm's members need to become familiar with the different stakeholders' interests. This can be achieved by learning (Kogut \& Zander 1992). This intention to learn causes professionals

to initiate observations about the surrounding environment including technical constraints and different parties' differing interests. This initiation triggers the formation of concepts for resolving the problems faced. Based on these concepts, professionals make judgments and are expected to take the correct ac-

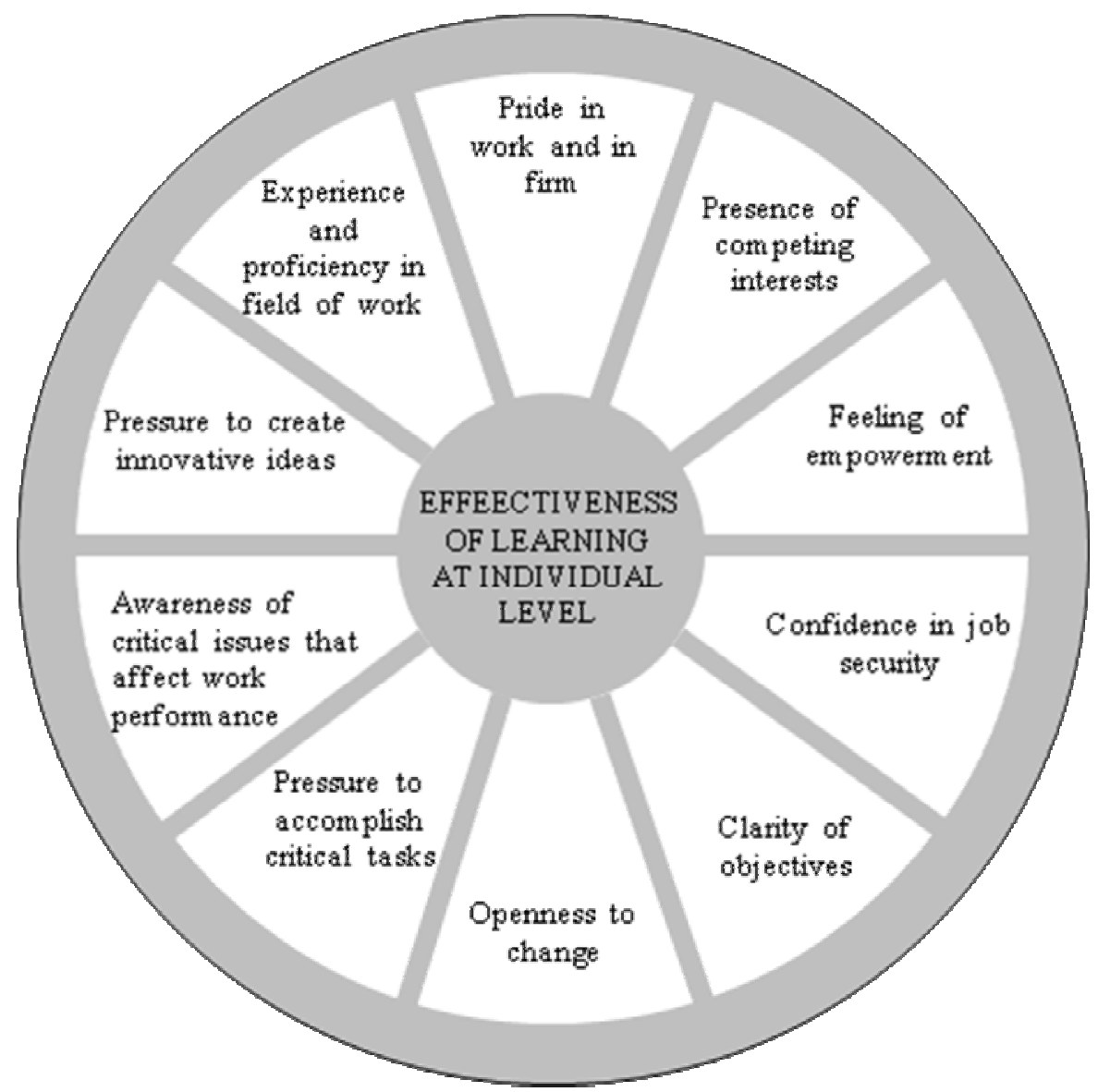

Figure 2. Assessment Model of the Effectiveness of the Architectural Professional's Learning Process

the firm and their part in it. On the other hand, the more professionals have pride in their work and their firm, the more eager they become to learn.

II. Presence of competing interests in projects: Especially in architectural design, professionals need to be generative, innovative, proactive, and energetic to contribute to the formation of a unique project that will comply with requirements dictated by the site and the owner. The diversity of competing interests affecting an architectural design (owner, regulating agencies, contractor, subcontractors, and engineers) requires a high level of positive energy and a significant effort to gather intelligence and to seek compromises. When a firm is faced with an tion when faced with similar problems in the future.

III. Feeling of empowerment: Empowerment and giving the chance to professionals to have key roles in a firm's strategic decisions may motivate professionals to learn and improve in related issues (Nesan 2004, Davey et al. 2002, Santos \& Powell 2001). Senge (1990) recognizes the importance of empowerment in the workplace, stating that empowered learners are vital to solving problems. Good learners can prevent or solve problems if they have full authority. While emphasizing the linkage between the concepts of "empowerment” and 'learning', Nesan (2004) argues that empowerment helps influence 
employees' behavior in seeking, managing and utilizing knowledge at work.

IV. Confidence in job security: In recent years, the concept of a job is being replaced by "individual skills, abilities, and competences" that make and keep professionals employable (Dweck 1986). Job security is not guaranteed. Because of fast changing trends and technology, work environments are evolving into continuous challenges. These challenges may be a source of motivation to learn and consequently acquire confidence in job security. Dweck (1986) describes motivational processes' influence on acquisition, transfer, and use of knowledge and skills. Lipshitz et al. (2002) argue that being in a continuous learning mode can let a professional to continuously adapt to new challenges. Kanter (1989) argues that security for the individual now lies not in employment but in employability. This leads individuals to take responsibility for their own career-long self-development (Hakim 1994). In this sense, learning is essential for professionals to maintain job security. Confident professionals can lead an open learning environment.

V. Clarity of objectives: Lipshitz et al. (2002) state the importance of a mission statement. They also argue that aligning employees to a certain strategic goal has an effect on learning. In architectural design projects, the first attempt is to learn the content of the project. Exploring the requirements of the project is a critical process that can well determine the success of the project. Initial attention is paid to define the scope of the project in terms of the goals and mission of the owner. Architectural professionals, who strive to learn an owner's mission, vision, and goals, are expected to develop successful designs.

VI. Openness to change: The typical job is based on repetitive action with limited need for additional knowledge but architectural design requires a state of readiness to adapt to rapidly changing project requirements and job descriptions. McAdam et al. (2000) argue that being ready and open to change enhances professionals' competitive advantage and allows them to move from status quo to continuous improvement. Architects are faced with emerging technologies in materials, methods of construction, structural systems, etc. that shorten the time spent designing a project. In addition, architects should be aware of new architectural styles, regulatory issues, and market conditions. The need for awareness of the professional environment triggers learning needs and motivates individuals to learn (Tjandra \& Tan 2002, Baldwin et al. 1997).

VII. Pressure to accomplish critical tasks: Architectural design involves internal and external tasks that are to be accomplished by professionals and that may be critical to the success of the project. While internal tasks are directly related to the process of design, external tasks have to do with the scope of the project, the owner's requirements, and relationships with local regulatory agencies. A professional must be capable of performing these critical tasks in order to survive in the work environment (Crossan et al. 1999). Accordingly, professionals are under pressure to learn the ways to fulfill these tasks.

VIII. Awareness of critical issues that affect work performance: Architectural professionals survive and thrive in their work environment depending on the quality of their performance. Being laid off or being promoted depends on how well they perform. Santos \& Powell (2001) concluded that the creation of an effective learning mood in construction is likely to happen if professionals are aware of issues that affect work performance. Architectural professionals who are aware of the critical issues that affect their work performance are likely to seek new knowledge about these issues in order to survive and climb up the organization. Awareness is one of the determining factors of the cognition process. According to Pitt (2008) critical issues in architectural design which affect the performance of the professionals are the project's functionality, constructability, aesthetics, durability, and sustainability. The project must also be respectful of users, and time, cost, and quality effective. Professionals in an architectural design firm must be knowledgeable in these areas.

IX. Pressure to create innovative ideas: Learning occurs when a professional detects a discrepancy between actual and expected results, and tries to correct the errors or challenge the underlying assumptions. The discrepancy can occur because of a change in the design and/or a shift in the project's scope. The challenge is to solve problems in a way that no one has ever attempted before. Variation on existing ideas forms innovation. A professional's innovative and creative approach is needed to tackle these problems. Therefore, developing new ideas is a core competence in solving problems. Cohen and Levinthal (1990) assert that learning orientation is significantly associated with innovative thoughts. Many scholars have indicated that learning orientation and innovativeness are highly correlated (e.g. Nonaka 1991, Garvin 1993, Goes \& Park 1997).

X. Experience and proficiency in field of work: According to Garvin (1993), individuals learn from their own experience and past history, and from the experiences and best practices of others. Professionals can learn from two sources, namely from experiences in the work environment and from external experiences. The Learning source in the internal en- 
vironment is firm's intellectual capital. Intellectual capital includes professionals' design experiences, knowledge, skills, and abilities, the firm's processes, procedures, routines, and the firm's memory. Learning in the work environment will benefit the professional in the short-run. On the other hand, external learning experiences are more varied. Varying and diverse character of external learning environment leads professionals to capture new knowledge that is gained through other individuals and firms. External learning sources are professionals from outside of the firm, personnel employed by educational agencies, owner, organizations, other parties participating in a project, and local regulatory agencies. Professionals may also observe the performance of their firm's competitors, asking questions not only about objective facts but also about the cause-and-effect relationships behind those facts.

While some of the ten factors presented in Figure 2 can be affected by individual perceptions, some are governed by environmental effects. However, when one examines these factors in depth, one finds that if a factor is predominantly affected by individual perceptions, it is also influenced to a certain extent by environmental conditions. Similarly, if a factor is predominantly affected by environmental conditions, it is also affected by individual perceptions. It is quite impractical to categorize these factors as "individual" and "environmental" as both conditions affect these ten factors in varying degrees.

\section{CONCLUSIONS}

To conclude, this paper has attempted to identify the individual learning factors to assess the effectiveness of the learning process of professionals employed by architectural design firms. These factors were identified in the light of the information in the current literature where the learning process and the barriers and drivers of individual learning are discussed. The factors affecting the learning process are shaped within the personal, physical, psychological, conceptual, and managerial conditions. The individual learning process starts with data acquisition, continues with the assessment of the information, and ends with the storage of knowledge. Ten factors were identified in this process, namely pride in work and in firm, presence of competing intents in projects, feeling of empowerment, confidence in job security, clarity of objectives, openness to change, pressure to accomplish critical tasks, awareness of critical issues that affect work performance, pressure to create innovative ideas, and experience and proficiency in field of work. These are the determining factors of the effectiveness of the learning process at individual level in architectural design firms. It is hoped that the learning process undertaken by professionals in architectural design firms is better understood after the factors identified in this study are known and can be assessed objectively. The factors identified in this study can be adapted to the other branches of the construction industry. The next step for management is to set in place a system that leads to group interaction among individuals, and that transforms the wisdom gained into organizational knowledge.

Future research should involve an empirical study of architectural design firms' performance relative to the effectiveness of the individual learning process. If one is able to measure the effectiveness of the learning process, one should also be able to assess its impact on company performance. Another area of the study involves the measurement of group learning, organizational learning, and the interfaces between individual-group-organizational learning.

\section{REFERENCES}

Alavi, S.B. \& McCormick, J. 2004. A cross-cultural analysis of the effectiveness of the learning organization model in school contexts. International Journal of Educational Management 18(7): $408-416$.

Baldwin, T. \& Danielson, C. \& Wiggenhorn, W. 1997. “The evaluation of learning strategies in organizations: From employee development to business redefinition.” The Academy of Management Executives 11(4): 47-58.

Bontis, N. \& Crossan, M.M. \& Hulland, J. 2002. Managing an organizational learning system by aligning stocks and flows. Journal of Management Studies 39(4): 437 - 469.

Bosch, J. 2004. Software architecture: The next step. Proceedings of First European Workshop on Software Architecture (EWSA 2004): 194-199. St Andrews, Scotland: SpringerVerlag.

Buckler, B. 1996. A learning process model to achieve continuous improvement and innovation. The Learning Organization 3(3): 31-39.

Chonkoa, L.B. \& Dubinskyb, A.J. \& Jonesd E. \& Robertsa J.A. 2003. Organizational and individual learning in the sales force: An agenda for sales research. Journal of Business Research 56(12): 935-946.

Cohen, W. M. \& Levinthal, D.A. 1990. Absorptive Capacity: A new perspective on learning and innovation. Johnson Graduate School of Management, Cornell University 35: 128-152

Crossan, M. \& Lane, H. \& White, R. 1999. An organizational learning framework: From intuition to institution. Academy of Management Review 24(3): 522-537.

Davey C.L. \& Powell J.A. \& Powell J.E. 2002. Cooper I. Action learning in a medium-sized construction company. Building Research \& Information 30(1): 5-15.

Dweck, C.S. 1986. Motivational processes affecting learning. American Psychologist 41(10): 1040-1048.

Easterby-Smith, M. 1997. Disciplines of organizational learning: Contributions and critiques. Human Relations 50(9): 1085-113.

Easterby-Smith, M. \& Araujo, L. 1999. “Organizational learning: Current debates and opportunities” In Esterby-Smith M., Burgoyne J., and Araujo L., Organizational learning 
and learning organization - Developments in theory and practice. London: Sage Publications.

Edmondson, A. \& Moingeon, B. 1998. "From organizational learning to the learning organization." Management Learning 29(1): 5-20

Ertmer, P.A.; Newby, T.J. 1996. The expert learner; strategic, self regulated and reflective. Instructional Science. 24(1): 1-24.

Garvin, D.A. 1993. Building a learning organization. Harvard Business Review July-August: 78-91.

Ghoshal, S. 1987. "Global strategy: An organizing framework". Strategic Management Journal 8(5): 425-40.

Grant, R.M. 1996. Prospering in dynamically competitive environments: Organizational capability as knowledge integration. Organization Science 4: 375-387.

Goes, J.B. \& Park, S.H. 1997. Interorganizational links and innovation: The case of hospital services. The Academy of Management Journal 40(3): 673-696

Hakim, C. 2004. We are all self-employed: How to take control of your career. Berrett-Koehler Publishers, Inc.

Halepota, H.A. 2005. Motivational theories and their application in construction. Cost Engineering 47(3): 14-18.

Herzberg, F \&.Mausner, B. \& Snyderman, B.B. 1959. The Motivation to Work. New York: Wiley.

Huang, J. 1999. Knowledge sharing and innovation in distributed design: Implications of Internet-based media on design collaboration. International Journal for Design Computing, Proceedings of DCNet '99.

Huber, G. 1991. Organizational learning: The contributing processes and the literatures. Organization Science: 88-115.

Kanter, R.M. 1989. 'The new managerial work', Harvard Business Review 67(6): 85-92.

Kikoski, C.K. \& Kikoski, J.F. 2004. The inquiring organization-tacit knowledge conversation and knowledge creation: Skills for 21st-century organizations. Greenwood Publishing Group.

Kogut, B. \& Zander, U. 1992. Knowledge of the firm, combinative capabilities, and the replication of technology. Organization Science 3: 383-397.

Kofman, F. 1992. Lecture slides. MIT Sloan School of Management. Cambridge, MA.

Kolb, D.A. 1976. Management and the learning process. California Management Review 18(3): 21-31.

Lehesvirta, T. 2004. Learning processes in a work organization: From individual to collective and/or vice versa? Journal of Workplace Learning 16(1/2): 92 - 100

Levitt, B. \& March J.G. 1988. Organizational learning. Annual Review of Sociology: 319-340.

Lipshitz, R. \& Popper, M. \& Friedman, V.J. 2002. A multifacet model of organizational learning. The Journal of Applied Behavioral Science 38(1): 78-98.

March, J.G. 1994. A primer on decision making. New York: The Free Press.

Martin, G. \& Pate J. \& Beaumont P. 2006. Company-based education programmes: What's the pay-off for employers? Human Resource Management Journal 11(4): 55 - 73.

Maslow, A. 1954. Motivation and personality. New York: Harper.

McAdam, R.; Stevenson, P. \& Armstrong, G. 2000. Innovative change management in SMEs: Beyond continuous improvement. Logistics Information Management 13(3): 138 149

McGregor, D. 1960. The Human Side of Enterprise. McGraw Hill, New York, NY.

Miner, A. \& Mezias, S. 1996. Ugly duckling no more: Pasts and futures of organizational learning research. Organization Science 7(1): 88-99.
Neisser, U. 1976. Cognition and reality. San Francisco: Freeman.

Nesan, LJ. 2004. Efficacy-information for implementing learning in construction. The Learning Organization 11(1): 4566.

Nonaka, I. 1991. “The Knowledge-Creating Company.” Harvard Business Review 69, November-December: 96-104.

Nonaka, I. \& Takeuchi, H. 1995. The knowledge- crating company. New York: Oxford University Press.

Piaget, J. 1970. Genetic epistemology. New York, NY: Columbia University Press.

Pitt, J.C. 2008. Design criteria in architecture. P.E. Vermaas et al. (eds.). Philosophy and Design. Dordrecht: Springer Netherlands.

Prieto, I.M. \& Revilla, E. 2005. Linking learning capacity and business performance: A research and empirical assessment. Instituto de Empresa Business School Working Paper No. WP05-14.

Santos, A. \& Powell, J.A. 2001. Effectiveness of push and pull strategies in construction management. Journal of Workplace Learning 13(2): 47-56.

Sarasvathy, S. \& Menon, A. 2004. Failing firms and successful entrepreneurs: Serial entrepreneurship as a temporal portfolio. Working Paper. University of Maryland. Smith School of Business.

Schein, E.H. 1993. How can organizations learn faster? The challenge of entering the green room. Sloan Management Review 34(2): 85-92.

Schön, D.A. 1983. The reflective practitioner: How professionals think in action. New York: Basic Books.

Schollhammer, H. 1991. Incidences and determinants of multiple entrepreneurship. In N. C. Churchill, W. D. Bygrave, J. G. Covin., D. L. Sexton, D. H. Slevin, K. H. Vesper, \& W. E. Wetzel (Eds.), Frontiers of Entrepreneurship Research. Wellesley: Babson College.

Senge, P.M. 1990. The fifth discipline: The art and practice of the learning organization. London: Century Business.

Senge, P. et. al. 1994. The fifth discipline field book: strategies and tools for building a learning organization. London: Nicholas Brealey Publishing.

Shanks, D.R. \& St. John, M.F. 2005. Learning from past experience: Footnotes on mindfulness and habitual entrepreneurship. Scandinavian Journal of Management 21(4): 451472.

Sharma, A. 2001. Factors related to strategic human resource management: A study of global organizations in India. Unpublished dissertation. Indian Institute of Technology. Delhi.

Shrivastava, P. 1983. A typology of organizational learning systems. Journal of Management Studies 20: 7-28.

Stewart, D. 2001. Reinterpreting the learning organization. The Learning Organization 8(4): 141-52.

Tjandra, I.K. \& Tan, W. 2002. Organizational learning in construction firms: The case of construction firms operating in Jakarta, Indonesia. Report on research conducted at $\mathrm{Na}$ tional University of Singapore, Singapore.

Tsang, E. 1997. Organizational learning and the learning organization: A dichotomy between descriptive and prescriptive research. Human Relations 50(1): 57-70.

Weick, K.E.; Sutcliffe, K.M.; Obstfeld, D. 1999. Organizing for high reliability: Processes of collective mindfulness. $R e-$ search in Organizational Behavior 21: 81-123.

White, F.M. \& Locke, E.A. 2009. Perceived determinants of high and low productivity in three occupational groups: A critical incident study. Journal of Management Studies 18(4): 375 - 388. 
